\title{
A Potent Halogen-Bonding Donor Motif for Anion Recognition and Anion Template Mechanical Bond Synthesis
}

\author{
Thanthapatra Bunchuay, Andrew Docker, Antonio J. Martinez-Martinez, and Paul D. Beer*
}

Dedicated to Professor Jean-Marie Lehn on the occasion of his $80^{\text {th }}$ birthday

\begin{abstract}
The covalent attachment of electron deficient perfluoroaryl substituents to a bis-iodotriazole pyridinium group produces a remarkably potent halogen bonding donor motif for anion recognition in aqueous media. Such a motif also establishes halogen bonding anion templation as a highly efficient method for constructing a mechanically interlocked molecule in unprecedented near quantitative yield. The resulting bis-perfluoroaryl substituted iodotriazole pyridinium axle containing halogen bonding [2]rotaxane host exhibits exceptionally strong halide binding affinities in competitive $50 \%$ water containing aqueous media, by a factor of at least three orders of magnitude greater in comparison to a hydrogen bonding rotaxane host analogue. These observations further champion and advance halogen bonding as a powerful tool for recognising anions in aqueous media.
\end{abstract}

Originating from its exploitation in solid state crystal engineering and in materials design, halogen bonding (XB), the highly directional, attractive intermolecular non-covalent interaction between an electrophilic halogen atom and a neutral or charged Lewis base, has begun to emerge as a powerful complement to the ubiquitous hydrogen bonding (HB) interactions for solution phase applications in catalysis, medicinal chemistry, anion transport, and anion recognition. ${ }^{[1-6]}$ Regarding the latter, we and others have demonstrated that XB hosts often display superior anion affinities and contrasting selectivities in comparison to $\mathrm{HB}$ host analogues. ${ }^{[7-11]}$ However, examples of XB host systems that function in competitive aqueous media remain extremely rare due in part to the challenging syntheses of such systems. ${ }^{[12,13]}$ This is especially the case with elaborate XB mechanically interlocked molecules (MIMs) which due to their unique topological threedimensional and highly preorganised cavities are capable of aqueous anion recognition..$^{[7,14,15]}$ Herein we report a novel, remarkably potent electron deficient perfluoroaryl substituted bisiodotriazole pyridinium XB donor motif (Figure 1a) which is demonstrated to dramatically increase the strength of $\mathrm{XB}$-anion interactions for recognition in aqueous media and the efficacy for an unprecedented near quantitative high yielding XB MIM synthesis of a rotaxane 1.PF using anion templation. a)
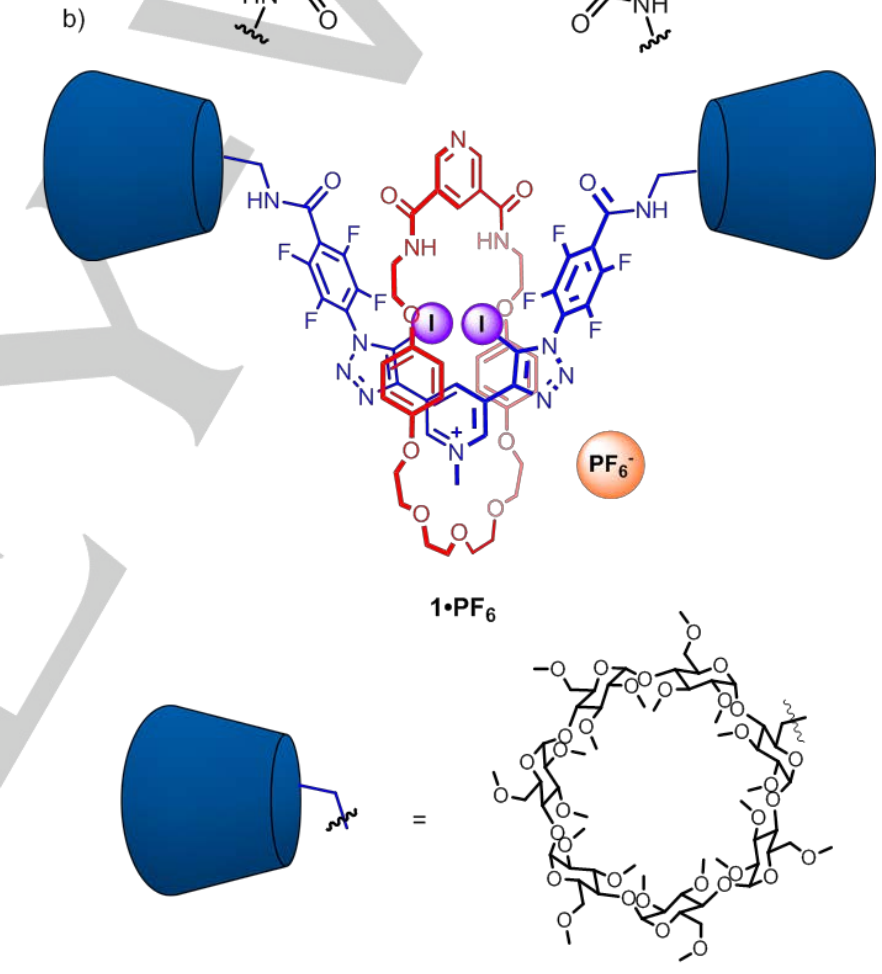

Permethylated $\beta$-cyclodextrin stopper group

Figure 1. a) Electron deficient perfluoroaryl substituted bis-iodotriazole pyridinium $\mathrm{XB}$ donor motif and $\mathrm{b}$ ) $\mathrm{XB}$ [2]rotaxane 1.PF 6 .
[*] Dr. T. Bunchuay, A. Docker, A. J. Martinez-Martinez, Department of Chemistry, University of Oxford, Chemistry Research Laboratory Mansfield Road, Oxford OX1 3TA (UK)

E-mail: paul.beer@chem.ox.ac.uk

Dr. T Bunchuay

Current Address: Faculty of Science Mahidol University, 272 Rama

IV Road, Ratchathewi District, Bangkok 10400 (Thailand) 
In order to investigate whether $\mathrm{XB}$ halide anion binding potency could be tuned via the covalent attachment of suitable electron withdrawing substituents, the synthesis of a series of $X B$ acyclic receptors consisting of a 3,5-bis-iodotriazole pyridinium motif functionalized with methylene linked benzylic and ester groups, and aryl linked benzene and perfluorinated benzene ester groups was undertaken initially. The monocationic pyridinium $X B$ receptors $\mathbf{2} \cdot \mathbf{P F}_{\mathbf{6}}, \mathbf{3} \cdot \mathbf{P F _ { 6 }}, \mathbf{4} \cdot \mathbf{P F}_{\mathbf{6}}$, and $\mathbf{5} \cdot \mathbf{P F}_{\mathbf{6}}$ (Figure 2 ) were prepared via copper(I)-catalysed azide-alkyne cycloaddition (CuAAC) reactions between appropriate azides and 3,5diiodoethynylpyridine, subsequent methylation with iodomethane and anion exchange. (The synthetic details are described in the $\mathrm{SI})$. The halide anion binding properties of the XB acyclic receptors, studied by ${ }^{1} \mathrm{H}-\mathrm{NMR}$ titration experiments in $\mathrm{d}_{6}$-DMSO, revealed chloride to form the strongest complexes correlating with halide charge density (Table 1 ).
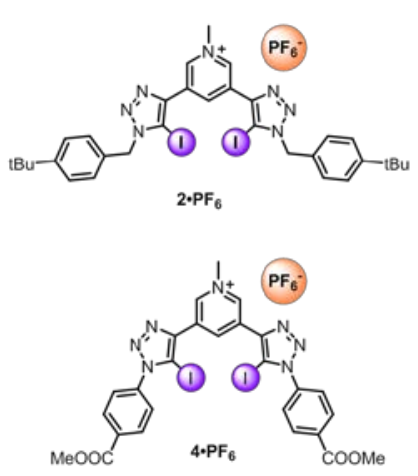

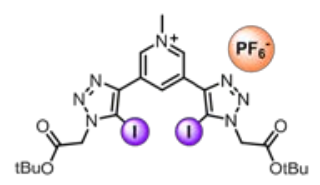

$3 \cdot \mathrm{PF}_{6}$

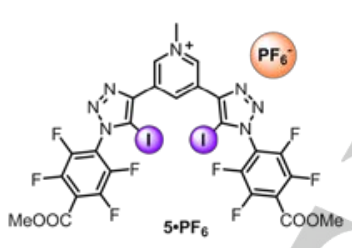

Figure 2. Structures of monocationic acyclic $X B$ bis-iodotriazole pyridinium receptors as their hexafluorophosphate salts $\left(\mathrm{PF}_{6}{ }^{-}\right)$.

It is noteworthy that the largest association constant magnitudes were observed with the perfluorinated arene functionalized receptor $\mathbf{5} \cdot \mathbf{P F}_{6}$ with all halides. This result highlights the inductive effect of the electron withdrawing perfluoroaryl spacer motifs polarising the iodine atoms of the bisiodotriazole XB donor groups facilitating strong XB-anion interactions.

Table 1. Anion association constant $\left(\mathrm{K}_{\mathrm{a}} / \mathrm{M}^{-1}\right)$ acyclic pyridinium bisiodotriazole receptors in $d_{6}$-DMSO, ${ }^{\text {[a] }}$

\begin{tabular}{|c|c|c|c|c|}
\hline Anion $^{[a]}$ & $2 \cdot \mathrm{PF}_{6}{ }^{[1]}$ & $3 \cdot \mathrm{PF}_{6}$ & $4 \cdot \mathrm{PF}_{6}$ & $5 \cdot \mathrm{PF}_{6}$ \\
\hline $\mathrm{Cl}^{-}$ & 387 & 403 & 429 & 1395 \\
\hline $\mathrm{Br}^{-}$ & 238 & 206 & 277 & 491 \\
\hline $1^{-}$ & 146 & 62 & 98 & 190 \\
\hline
\end{tabular}

[a] Anions added as their TBA salts, values of $K_{a}$ determined using the WinEQNMR2 software ${ }^{[16]}$ using a 1:1 host-guest binding model; errors $( \pm)$ less than $10 \%$. $d_{6}$-DMSO, $T=298 \mathrm{~K}$
Single crystals suitable for X-ray diffraction studies were obtained for the halide salts $\mathbf{5} \cdot \mathbf{C l}$ and $\mathbf{5} \cdot \mathbf{I}$. In both structures the acyclic receptor adopts a close triazole-I conformation encapsulating the anion guest through strong halogen bondhalide interactions (Figure 3, see SI for CCDC) as indicated by triazole- $\mid \cdots X^{-}$interatomic distances significantly shorter than the sum of the van der Waals radii (see Table 2). ${ }^{[17]}$
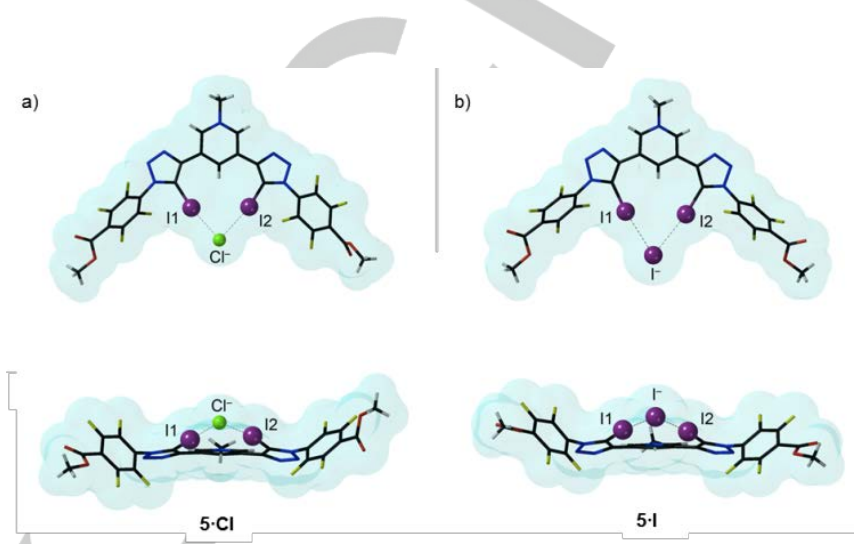

Figure 3. Structures of monocationic acyclic XB bis-iodotriazole pyridinium receptors $5^{+}$as the; $a$ ) chloride and b) iodide salt.

Table 2. $X B$ bond lengths and percentage shortening of the sum of the van der Waals radii $(\% \mathrm{VdW}) .{ }^{[17]}$

\begin{tabular}{lcc}
\hline Guest Anion & $\begin{array}{c}\text { interatomic distances } \\
(1 \cdots \times-\mid \AA)^{[\mathrm{a}]}\end{array}$ & \%vdW \\
\hline $\mathrm{Cl}^{-}$ & $3.1419(6), 3.0079(6)$ & $83 \%, 79 \%$ \\
$\mathrm{I}^{-}$ & $3.4010(3), 3.3522(3)$ & $81 \%, 80 \%$ \\
\hline
\end{tabular}

[a] Calculated errors given in parenthesis.

The XB donor bis-iodotriazole pyridinium structural motifs of the acyclic receptors were integrated into a bis-permethylated $\beta$ cyclodextrin stoppered axle component for respective $\mathrm{XB}$ [2]rotaxane construction using a chloride anion template amide condensation clipping rotaxanation reaction. Axles $6 \cdot \mathbf{C l}, 7 \cdot \mathbf{C l}$, 8. $\mathrm{Cl}$ were each stirred with an equimolar amount of bis-amine macrocycle precursor ${ }^{10}{ }^{[18]}$ and $\mathrm{NEt}_{3}$ in dry $\mathrm{CH}_{2} \mathrm{Cl}_{2}$ at $0^{\circ} \mathrm{C}$, whereupon addition of 3,5-bis-chlorocarbonyl pyridine $\mathbf{1 1}$ afforded, after purification by preparative thin layer silica gel chromatography and anion exchange to their $\mathrm{PF}_{6}{ }^{-}$salts, the target $\mathrm{XB}$ [2] rotaxanes $\mathbf{1 2} \cdot \mathbf{P F}_{\mathbf{6}}, \mathbf{1 3} \cdot \mathbf{P F}_{\mathbf{6}}$ and $\mathbf{1} \cdot \mathbf{P F}_{\mathbf{6}}$ in respective isolated yields of $40 \%, 45 \%$ and $91 \%$ (Scheme 1 ). In contrast, the combined effect of $\mathrm{XB}$ and perfluoroaryl group incorporation in effective rotaxane formation was further highlighted by $a$ significantly lower $42 \%$ isolated yield of the HB rotaxane $\mathbf{1 4} \cdot \mathbf{P F}_{6}$, obtained from using perfluoroaryl $\mathrm{HB} \mathbf{9} \cdot \mathbf{C l}$ axle as a template, compared to the $91 \%$ yield of $X B$ rotaxane $1 \cdot \mathbf{P F}_{6}$. 

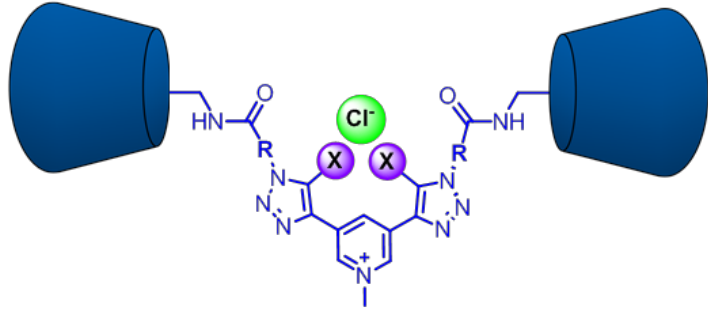

$\mathbf{R}=$

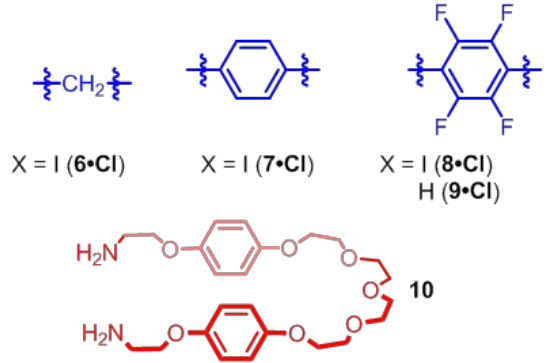<smiles>O=C(Cl)c1cncc(C(=O)Cl)c1</smiles>

11

$\mathrm{NEt}_{3}, \mathrm{DCM}$

(ii) $0.1 \mathrm{M} \mathrm{NH}_{4} \mathrm{PF}_{6}(\mathrm{aq})$

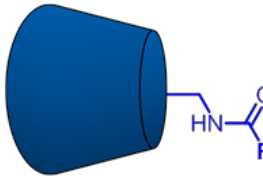

(N)

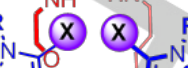

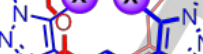

$i_{i n}^{n} \cdot i n$

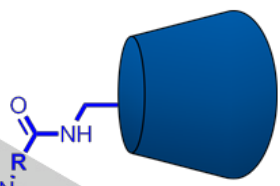

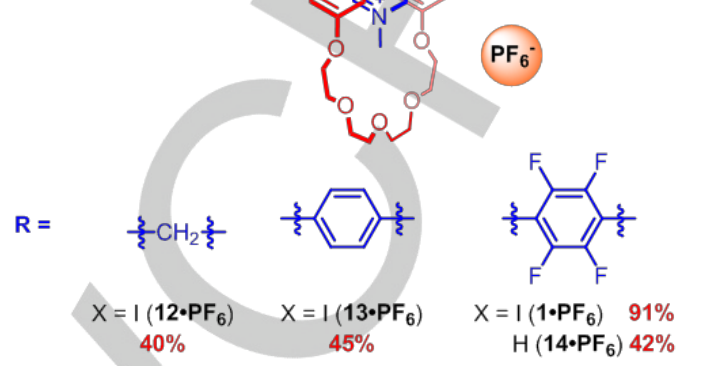

Scheme 1. [2]Rotaxane synthesis via chloride template amide condensation

Clearly the perfluorinated benzene functionalized $X \mathrm{~B}$ axle 8. $\mathbf{C l}$ acts as the most efficient anion template for rotaxane synthesis as evidenced by the impressive $91 \%$ yield of [2]rotaxane $\mathbf{1} \cdot \mathbf{P F}_{6}$. By contrast, the axles containing the nonfluorinated aromatic and alkyl spacers result in [2]rotaxane formation in the typical yield range for the anion template method of $40-60 \% \cdot{ }^{[7,15,18]}$ Taking into account the chloride anion association constant data shown in Table 1, where the acyclic XB receptor $\mathbf{5} \cdot \mathbf{P F}_{6}$ by virtue of the electron-withdrawing perfluoroaryl spacer motifs forms the strongest association with chloride, there is an obvious correlation of chloride anion association strength with yield of rotaxane formation. Notably, the observed $>90 \%$ yield for the preparation of [2]rotaxane $\mathbf{1} \cdot \mathbf{P F}_{6}$ via this $X B$ anion template clipping method matches the highest yields obtained for

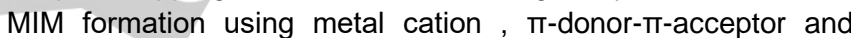
hydrogen bond templates. ${ }^{[19-26]}$

a)
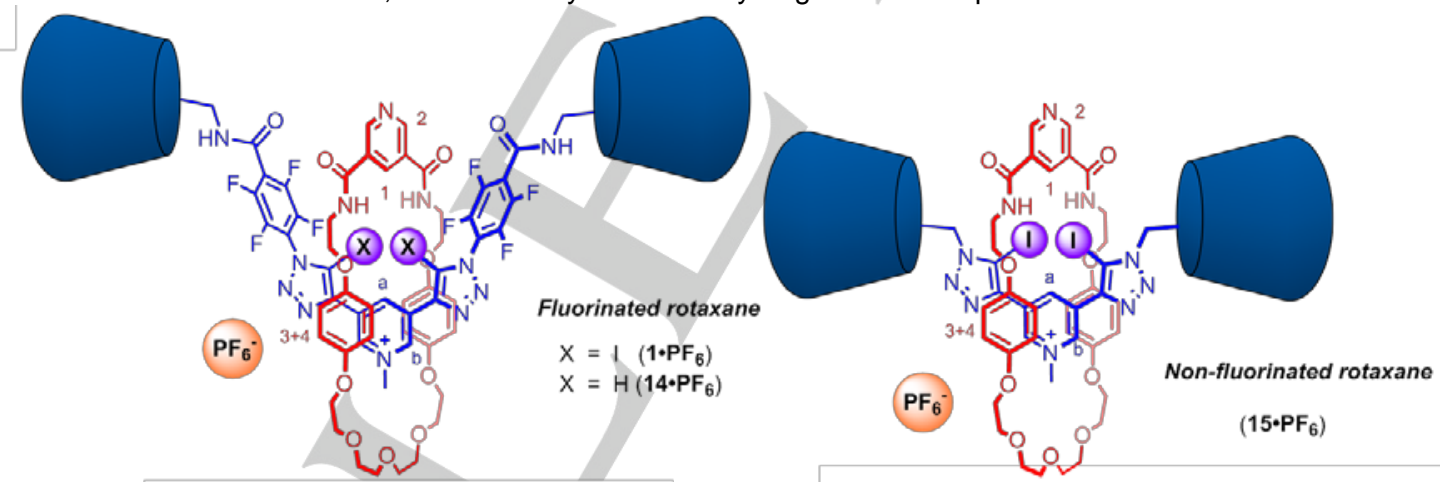

b)

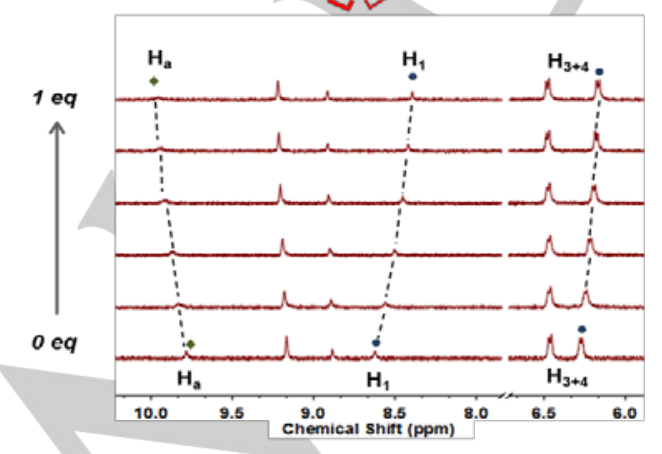

c)

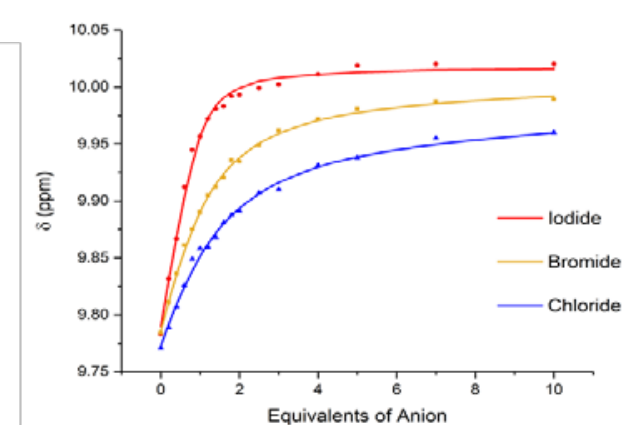

Figure 4 a) Perfluorinated and non-fluorinated [2] rotaxane host molecules b) Truncated ${ }^{1} \mathrm{H}-\mathrm{NMR}$ of 1-PF $\mathrm{P}_{6}$ in $\mathrm{D}_{2} \mathrm{O}: \mathrm{d}_{6}$ - $\mathrm{Acetone}(1: 1)$ upon addition of iodide anion as its TBA salt. c) Anion Binding isotherm of $\mathbf{1} \cdot \mathbf{P F}_{6}$, [host] $=1 \mathrm{mM}$ and [guest] $=50 \mathrm{mM}(500 \mathrm{MHz}, 298 \mathrm{~K})$. 
Table 3. Anion association constant $\left(\mathrm{K}_{\mathrm{a}} / \mathrm{M}^{-1}\right)$ for acyclic and [2]rotaxane hosts in $\mathrm{D}_{2} \mathrm{O}: d_{6}-$ Acetone (1:1). ${ }^{[\mathrm{a}]}$

\begin{tabular}{|c|c|c|c|c|}
\hline \multirow{2}{*}{ Entry } & \multirow{2}{*}{ Receptors } & \multicolumn{3}{|c|}{$\mathrm{K}_{\mathrm{a}}\left(\mathrm{M}^{-1}\right)$ in 1:1 $\mathrm{D}_{2} \mathrm{O} / d_{6}$-Acetone } \\
\hline & & Chloride & Bromide & lodide \\
\hline \multicolumn{5}{|c|}{ Perfluorinated Hosts } \\
\hline 1 & Monocationic XB Perfluoroaryl Rotaxane $\mathbf{1} \cdot \mathrm{PF}_{6}$ & 930 & 1727 & $>10^{5}$ \\
\hline 2 & Monocationic HB Perfluoroaryl Rotaxane $\mathbf{1 4} \cdot \mathbf{P F}_{6}$ & $N B^{b}$ & $N B^{b}$ & 63 \\
\hline \multicolumn{5}{|c|}{ Non-fluorinated Hosts } \\
\hline 3 & Monocationic XB Rotaxane 15· $\mathbf{P F}_{6}$ & 150 & 436 & 1036 \\
\hline
\end{tabular}

a Anions added as TBA salts, errors $( \pm$ ) less than $10 \%, 1: 1$ association constants calculated using WinEqNMR2 software, $\underline{2}$ monitoring the perturbation of the internal pyridinium proton $\mathrm{H}_{\mathrm{a}}(500 \mathrm{MHz}, 298 \mathrm{~K}) .{ }^{\mathrm{b}} \mathrm{NB}=\mathrm{No}$ binding.

The halide anion recognition properties of XB monocationic rotaxanes together with a $\mathrm{HB}$ rotaxane analogue and axle were investigated using ${ }^{1} \mathrm{H}-\mathrm{NMR}$ titration experiments in $\mathrm{D}_{2} \mathrm{O}: d_{6^{-}}$ acetone (1:1). With all XB rotaxanes the addition of halide anion caused significant perturbations of interlocked cavity proton resonances $\left(\mathrm{H}_{\mathrm{a}}\right.$ and $\left.\mathrm{H}_{1}\right)$ (Figure $5 b$ ). The downfield shift of the axle component internal pyridinium proton $\left(\mathrm{H}_{\mathrm{a}}\right)$ and the upfield shift of the internal pyridine proton $\left(\mathrm{H}_{1}\right)$ from the macrocycle component were monitored as a function of equivalents of anion added (Figure 5c). WinEQNMR2 analysis of the titration data for both $\mathbf{1} \cdot \mathbf{P F}_{6}$ and $\mathbf{1 4} \cdot \mathbf{P F}_{6}$ revealed $1: 1$ stoichiometric association constants for halide anions (Table 3 ).

In the highly competitive $50 \%$ aqueous mixture, the halogen bonding rotaxane 1- $\mathrm{PF}_{6}$ displays remarkably strong binding for $\mathrm{Cl}^{-}$, $\mathrm{Br}^{-}$, and $\mathrm{I}^{-}$anions. Indeed, the association constant for iodide binding is $>10^{5} \mathrm{M}^{-1}$, whilst those of bromide and chloride are 1727 $\mathrm{M}^{-1}$ and $930 \mathrm{M}^{-1}$ (Table 3, Entry 1), respectively. This preferential binding to the larger and less highly hydrated halide anions is presumably governed by the Hofmeister series bias. ${ }^{[27-29]}$ In contrast, the halide anion recognition strength of the hydrogen bonding rotaxane analogue $\mathbf{1 4} \cdot \mathbf{P F}_{6}$, where iodotriazole groups are substituted with $\mathrm{C}-\mathrm{H}$ prototriazole motifs is dramatically diminished, demonstrating only very weak affinity to $\mathrm{I}^{-}$and no binding for $\mathrm{Cl}^{-}$and $\mathrm{Br}^{-}$(Table 3, Entry 2). The remarkable enhancement of halide complexation by $X B \mathbf{1} \cdot \mathbf{P F}_{6}$ rotaxane by at the very least three orders of magnitude in comparison to $\mathrm{HB}$ rotaxane $\mathbf{1 4} \cdot \mathbf{P F}_{6}$ illustrates again the superiority of halogen bonding over hydrogen bonding in aqueous anion recognition. $[7,9,12-15]$

Finally, in an effort to elucidate the effect of incorporating the perfluoroaryl motif into the axle component of $\mathbf{1} \cdot \mathbf{P F}_{6}$, the halide anion binding properties of monocationic $X B$ rotaxane 15. $\mathbf{P F}_{6}$ were determined (Table 3 Entry 3 ). As expected, 1.PF demonstrates notable enhancement of halide binding, with the strength of iodide complexation at least two orders of magnitude greater than $\mathbf{1 5} \cdot \mathbf{P F}_{6}$ rotaxane (Table 3 , Entry 1 and 3 ), which can be attributed to the rigid, electron deficient and hydrophobic nature of the perfluoroaryl substituents of the pyridinium bis- iodotriazole axle component of $\mathbf{1} \cdot \mathbf{P F}_{6}$, facilitating in particular the amplified potency of XB donor - halide anion interactions.

In conclusion, the covalent attachment of electron deficient perfluoroaryl substituents to a bis-iodotriazole pyridinium group produces a powerful halogen bonding donor motif capable of halide anion recognition in aqueous media. For the first time, a near quantitative isolated yield of a discrete anion template directed assembly of a MIM host structure is achieved via exceptionally strong XB donor-chloride interactions. Moreover, the chloride anion association strength of the axle component's XB donor motif correlates with rotaxane formation yield. Importantly, anion binding studies in competitive 50\% water containing aqueous media reveal the monocationic $X B$ rotaxane 1. $\mathrm{PF}_{6}$ to exhibit remarkable halide binding affinities at least three orders of magnitude greater than a HB rotaxane analogue. These observations provide further evidence for highlighting $X B$ as a novel tool for achieving anion recognition in aqueous media.

\section{Acknowledgements}

T.B. would like to thank the Development and Promotion of Science and Technology Talents (DPST) Project, Thailand, for a full student scholarship. A.D. thanks the EPSRC for a studentship. The authors thank Dr. Nader Amin and Dr. Jason Lim, University of Oxford, for helpful discussions.

Keywords: Anion Recognition • Halogen Bonding • Rotaxanes • Supramolecular

[1] J.-P. Gliese, S. H. Jungbauer, S. M. Huber, Chem. Commun. 2017, 53, 12052-12055

[2] S. Schindler, S. M. Huber, in Halog. Bond. II Impact Mater. Chem. Life Sci. (Eds.: P. Metrangolo, G. Resnati), Springer International Publishing, Cham, 2015, pp. 167-203.

[3] R. Wilcken, M. O. Zimmermann, A. Lange, A. C. Joerger, F. M. Boeckler, J. Med. Chem. 2013, 56, 1363-1388.

[4] A. V. Jentzsch, D. Emery, J. Mareda, S. K. Nayak, P. Metrangolo, G. Resnati, N. Sakai, S. Matile, Nat. Commun. 2012, 3, 905.

[5] R. Tepper, U. S. Schubert, Angew. Chem. Int. Ed. 2018, 57, 6004-6016.

[6] A. M. S. Riel, D. A. Decato, J. Sun, C. J. Massena, M. J. Jessop, O. B. Berryman, Chem. Sci. 2018, 9, 5828-5836. 
[7] M. J. Langton, S. W. Robinson, I. Marques, V. Félix, P. D. Beer, Nat. Chem. 2014, 6, 1039-1043.

[8] S. W. Robinson, C. L. Mustoe, N. G. White, A. Brown, A. L. Thompson, P. Kennepohl, P. D. Beer, J. Am. Chem. Soc. 2015, 137, 499-507.

[9] J. Y. C. Lim, T. Bunchuay, P. D. Beer, Chem. - Eur. J. 2017, 23, 47004707.

[10] N. B. Wageling, G. F. Neuhaus, A. M. Rose, D. A. Decato, O. B. Berryman, Supramol. Chem. 2016, 28, 665-672.

[11] S. Chakraborty, R. Dutta, P. Ghosh, Chem. Commun. 2015, 51, 1479314796

[12] J. Y. C. Lim, P. D. Beer, Chem. Commun. 2015, 51, 3686-3688.

[13] S. P. Cornes, M. R. Sambrook, P. D. Beer, Chem. Commun. 2017, 53, 3866-3869.

[14] S. W. Robinson, P. D. Beer, Org. Biomol. Chem. 2016, 15, 153-159.

[15] M. J. Langton, I. Marques, S. W. Robinson, V. Félix, P. D. Beer, Chem. - Eur. J. 2016, 22, 185-192.

[16] M. J. Hynes, J. Chem. Soc. Dalton Trans. 1993, 2, 311-312.

[17] A. Bondi, J. Phys. Chem. 1964, 68, 441-451.

[18] L. M. Hancock, L. C. Gilday, S. Carvalho, P. J. Costa, V. Félix, C. J. Serpell, N. L. Kilah, P. D. Beer, Chem. - Eur. J. 2010, 16, 13082-13094.

[19] F. G. Gatti, D. A. Leigh, S. A. Nepogodiev, A. M. Z. Slawin, S. J. Teat, J. K. Y. Wong, J. Am. Chem. Soc. 2001, 123, 5983-5989.

[20] J. E. M. Lewis, F. Modicom, S. M. Goldup, J. Am. Chem. Soc. 2018 140, 4787-4791.

[21] M. Weck, B. Mohr, J.-P. Sauvage, R. H. Grubbs, J. Org. Chem. 1999 $64,5463-5471$.

[22] J. Wu, K. C.-F. Leung, J. F. Stoddart, Proc. Natl. Acad. Sci. 2007, 104 17266-17271.

[23] J. E. M. Lewis, J. Winn, L. Cera, S. M. Goldup, J. Am. Chem. Soc. 2016, 138, 16329-16336.

[24] B. Mohr, J.-P. Sauvage, R. H. Grubbs, M. Weck, Angew. Chem. Int. Ed. Engl. 1997, 36, 1308-1310.

[25] S. Li, M. Liu, J. Zhang, B. Zheng, C. Zhang, X. Wen, N. Li, F. Huang, Org. Biomol. Chem. 2008, 6, 2103-2107.

[26] K. Zhu, V. N. Vukotic, N. Noujeim, S. J. Loeb, Chem. Sci. 2012, 3, 3265-3271.

[27] C. L. D. Gibb, E. E. Oertling, S. Velaga, B. C. Gibb, J. Phys. Chem. B 2015, 119, 5624-5638.

[28] P. Sokkalingam, J. Shraberg, S. W. Rick, B. C. Gibb, J. Am. Chem. Soc. 2016, 138, 48-51.

[29] F. Hofmeister, Arch. Für Exp. Pathol. Pharmakol. 1888, 24, 247-260. 


\section{COMMUNICATION}

The covalent appendage of electron deficient perfluoroaryl substituents to a bis-iodotriazole pyridinium group produces a powerful halogen bond donor. Using this motif, halogen bonding anion templation is demonstrated as a highly efficient method for constructing a rotaxane in near quantitative yield, capable of strong halide binding in 50\% water aqueous media.

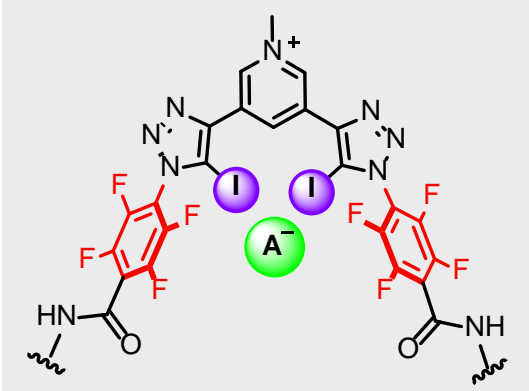

Thanthapatra Bunchuay, Andrew Docker, Antonio J. Martinez-Martinez, and Paul D. Beer*

Page No. - Page No.

A Remarkably Potent HalogenBonding Donor Motif for Anion Recognition and Anion Template Mechanical Bond Synthesis 